\title{
Un ejemplo de modulación moral en Aleixandre: "En la plaza"
}

José Luis Cam pal Fernández

Real Instituto de Estudios Asturianos

\section{Resumen}

El poema deV icenteAleixandre "En la plaza" representa una de las cumbres de su producción como texto civil, de modulación moral, en el que el autor entiende la vida como esfuerzo y lucha; nos encontramos ante una al egoría atemporal que exalta la vida vivida al máximo, una llamada a la coexistencia pacífica sin diferencias, en la que el poeta defiende que vivir como parte integrada en la sociedad reafirma nuestra identidad individual cuando se llega a formar parte de la comunidad.

Palabras Claves: Poesía española del siglo XX, al egoría cívica, solidaridad y conciencia.

\section{ABSTRACT}

The poem by Vicente Aleixandre "En la plaza" (In the square) represents one of the peaks of his work as a civic text, of moral modulation, where the autor sees life as endeavour and struggle; we find ourselves before an intemporal alegorie which exal ts life lived to the full, a call to peaceful coexistence with no differences, in which the poet defends that living as an integrat part of society reasserts our identity as an individual when it becomes part of the comunity.

KEYWORDS: Spanish poetry of twentieth century, civic allegory, solidarity and moral sense. Recibido: 07.11.2002. Aceptado: 10.12.2002.

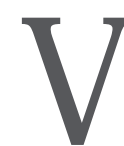

ICEN TE ALEIXAN DRE (1898-1984) fue uno de los más genuinos representantes del Ilamado "Grupo del 27", el que dio en consensuarse como una segunda edad dorada de las letras españolas, y recibió, para mejor afianzar la coincidencia crítica, el Premio N obel de Literatura en 1977, cuando sus aportaciones poéticas podían considerarse como totalmente cumplimentadas. Aleixandre permaneció en España al terminar la guerra civil, por lo que la ausencia de la experiencia del exilio va a facilitar que desarrolle sin interrupciones una obra que se muestra en evolución y cohesionada en sus 
fundamentos éticos y estéticos, una trayectoria beneficiada por la continuidad pero no estancada en la repetición de unos modelos determinados. La visión del mundo que aprehende Aleixandre en sus poemas hace factible una división de sus contribuciones en varias etapas, que pueden ser perfectamente tres, aunque haya estudiosos que opten por reducirlas sólo a dos.

"En la plaza" es un poema inscribible en su segunda etapa, que se inicia en 1954 con H istoria del corazón, un libro en el que se rinde tributo al amor humano desjerarquizado, y que marca una separación respecto al período anterior porque la lengua poética desciende a territorios más humanizadores y la expresión se hace más próxima y actual, más directa y accesible. Aleixandre, que siempre defendió la función de la poesía como conocimiento, parece trazar en esta etapa un anhelo de "reconocerse" no sólo en el mundo sino en quienes lo pueblan, como si quisiera transmitirnos queúnicamente desde la afirmación de uno dentro de la colectividad es posibleel conocimiento personal del individuo. El hombre no ha dejado de ser un ser frágil abatido por las circunstancias y desgraciado, pero ya ha aparecido el coraje que conlleva la esperanza de vivir en colectividad. El yo poético se transmuta en un yo compartido y compartidor que hace suyos los anhelos eilusiones de todos los miembros de la comunidad. La que está contenida en H istoria del corazón es una poesía social de atención cívica, una poesía de contención moral, que aspira a que el esfuerzo de todos sirva para configurar un mundo menos caótico y algo más justo o mejorable. Ello conviertea esta segunda etapa en un referente de humanismo y de ideal ismo, como han visto la mayoría de los editores literarios del autor sevillano, como A. D uque Amusco.

H istoria del corazón - título con el que Luis Cernuda no comulgaba, por sus connotaciones rosáceas, pese a considerar espléndida a esta obra de Alei xandrefue escrito entre el 14 demayo de 1945, al poco de publicarse Sombra del paraíso, y el 24 de agosto de 1953', si bien el mayor número decomposiciones, entre las que se halla "En la plaza", se redactaron entre el otoño de 1951 y el invierno de 1952. El libro lo editó Espasa-Calpe en 1954 y está dedicado a Dámaso Alonso: "Amigo de todas las horas, seguro en toda la vicisitud, desde la remota adolescencia", y lo hace el poeta "cumplido y rebasado un tercio de siglo de fraternal amistad". Se compone de seis partes, la última en realidad es sólo un poema - "M irada final (M uerte y reconocimiento)"-, cuyo antecedente podría rastrearse en Sombra del paraí so, aunque ambos títulos contengan planteamientos y objetivos en modo alguno parangonables. Historia del corazón es un poemario de orientación realista que hinca los pies en el mundo contemporá-

${ }^{1}$ Bousoño, Carlos. La poeśa de Vicente Aleixandre, M adrid, Editorial Gredos, Biblioteca Románica H ispánica, “Estudios y ensayos”, № 27, 1956, pp. 427-428. 
neo, si bien rehuyendo las contextualizaciones efímeras y empobrecedoras de los hechos y personas puntuales, y por lo tanto caducas, pero también sin re nunciar del todo a las obsesiones estilísticas del poeta sevillano. El eminente filólogo Fernando Lázaro C arreter dijo en una conferencia sobreAleixandreque en estepoemario "sus ojos [los del poeta] se vuelven hacia el hombre circunstancial, pero [para] indagar verdades humanas más duraderas, más permanentes"2.

H istoria del corazón es un libro que Bousoño entronca en su estudio clásico sobre Aleixandre 3 con un tipo de poesía donde se conjugan lo afectivo y el mundo de lo sensorial. El poeta habla en los 48 poemas del libro del difícil pero entusiasmante y esperanzador proyecto humano de vivir, un vivir provisional, un vivir esperanzante que está al entado por la cada vez mayor reducción de la soledad, para lo que encuentra cobijo en un amor multiforme y básicamente sinónimo de acompañamiento; el amor de H istoria del corazón es predominantemente erótico, aunque no creo que sea ése el caso del poema "En la plaza", a no ser que se entienda el símbolo del agua en su dimensión sexual. A propósito de la trascendencia del amor, afirma Leopoldo de Luis que en $\mathrm{H}$ istoria del corazón "la existencia tórnase una gran tarde toda del amor"4.

La trascendencia otorgada a la vida invita al poeta a recrear pasajes de su propia vida en conexión con la de quienes le rodean, de forma que esa historia del corazón a que al ude el título no será solamente la suya, sino la suma de la de todos; rotular su entrega con el término H istoria hablaría de su interés por la coetaneidad. En un poema de H istoria del corazón titulado “El poeta canta por todos", escribe:

Son miles de corazones que hacen un único corazón que telleva 5 .

El tema de la vida no se desliga en el poemario del tema del tiempo, dado que lo restrictivo por fuerza biológica del período vital impone un sentimiento de fugacidad. Además, el poeta quiere, desde la madurez, apresar la vida palpitante en todos sus estadios, por lo cual nos topamos con poemas donde las figuras centrales de los mismos son niños, adolescentes, adultos o viejos, es de cir, todos los escal ones de la vida. La evanescencia del vivir terreno, su limitada duración, provoca en el poeta una admiración no exenta de desazón. En H istoria del corazón, y más concretamente en la partea la que pertenece el poema “En

${ }^{2}$ Lázaro Carreter, Fernando: Introducción a la poeśa deVicenteAlei xandre, M adrid, Fundación Universitaria Española, 1979, p. 21.

${ }^{3}$ Vid. nota 1.

"Luis, Leopoldo de: "Introducción", en Aleixandre, Vicente: Antología poética, M adrid, Alianza Editorial, "El libro de bolsillo", № 647, 5ạ edición, 1980, p. 24.

${ }^{5} \mathrm{H}$ istoria del corazón, M adrid, Espasa-Calpe, 4a edición [1977], p. 64. 
Ia plaza", se entiende la vida como esfuerzo y lucha porque la vida para el poeta no es en su totalidad terriblemente negra ni esplendentemente diáfana, sino impredecible, voluble, cambiante y contradictoria; una vida cuya concreción temporal no le desanima ni detiene a la hora de exprimirle sus jugos; un vivir que es comparado en el poema "Entre dos oscuridades, un relámpago" con cruzar un desierto:

Echaremos de nuevo a andar. No sé si solos, no sé si acompañados.

$\mathrm{N}$ o sé si por estas mismas arenas que en una noche hacia atrás de nuevo

[recorreremos ${ }^{6}$.

El hombre está en la sombra, pero no quiere sumirse permanentemente en ella, sino que manifiesta su deseo de ocupar un lugar bajo la luz. Las visiones imaginísticas de la etapa panteísta, ubicadas en el recuerdo del pasado, han sido ahora reemplazadas, como ocurre en el poema que comentamos, por la concatenación del presenteo los presentes que invocando hechos de un pasado reciente se proyectan hacia el futuro. Cuando apareció el libro, el catedrático de la U niversidad de Barcelona Antonio Vilanova escribió en una reseña de la revista D estino que "al trocar Aleixandre la contemplación jubilosa del mundo y del amor por una meditación sobrela vida, sehaceeco delos problemas queatenazan desde siempre a la condición humana"7.

"En la plaza" está incluido en la segunda de las seis partes en que se organiza H istoria del corazón, y quetiene por epígrafe "La mano extendida", queesla más extensa de todas ellas, y en la que la temática amorosa cede relevancia al sentido del vivir en comunidad como parte de un todo humano más ensanchado. El poema, que según Lázaro Carreter era el preferido de Aleixandre ${ }^{8}$, lo escribió el 14 de noviembre de 1952. "En la plaza” puede interpretarse como una al egoría intemporal a favor de la vida vivida, donde la sucesión de acciones brota de la valoración que el poeta hace de una constatación, como es la de que vivir integrado, respal dado o acompañado, reafirma nuestra entidad individual al hacerla comunitaria. Y para enmarcarlo todo se corporeiza esta convicción en una marcha popular, en una manifestación espontánea, que, según confesión propia de Aleixandre a J osé Luis C ano, tuvo su embrión en la marcha del pueblo madrileño que el 14 de abril de 1931 se encaminó a la Puerta del Sol para celebrar la proclamación de la II República9. Un motivo como el de la manifestación que

${ }^{\natural}$ bídem, p. 185.

'Vilanova, Antonio: Poeśa española. Del 98 a la posguerra, Barcelona, Editorial Lumen, "Palabra crítica", № 25, 1998, p. 288.

${ }^{8} \mathrm{Vid}$. nota 2, p. 24.

${ }^{9} \mathrm{C}$ ano, José Luis: Vicente Aleixandre, M adrid, M inisterio de Cultura, 1981, p. 26. 
seprestabaal dinamismo, adopta en manos deAleixandre una cadencia expositiva nada estruendosa, que fomenta la introspección más que el vocerío y lo inconsecuente. A pesar de ese anclaje espacio-temporal en el impulso creativo primigenio, el texto presenta una total ausencia de referentes explícitos, porque el autor pretende saltar por encima de las motivaciones históricas para instalarse en una interpretación más universalizante y plurisignificativa de la realidad.

El poema de Aleixandre es una llamada a la convivencia pacífica sin distinciones, al vivir en plenitud el momento y calladamente, pero se canta no la vida en exclusiva de unos hombres y un país en particular, aunque el caso de España está muy presente, sino el de toda la humanidad. El poeta se reconoce como uno más, no se erige en guía, sino en embebecido instigador de la reunión colectiva, que se le ofrece en los primeros compases del poema y a la que accede sin demora. Se canta una unidad silenciosa y natural, espontánea, noble y sin protagonismos individualistas, "hermosamente humilde", diceAleixandre en el primer verso. "En la plaza" es una celebración de la fraternidad, de que en la unidad se abre un resquicio al bien de la sociedad; una celebración, igualmente, de la equidad, del abrazo solidario y del remozamiento espiritual. El poeta es un ser social por antonomasia y busca en la unión con los otros una comunión ética, que ponga remedio a su soledad. La apuesta a favor del vivir colectivo se aprecia en otros poemas de H istoria del corazón como "Vagabundo continuo"10.

La estructura métrica del poema respondea esquemas netamentealeixandrinos, ya quenosencontramos con unaseriede versículos, preferencialmenteparoxítonos, de diferente número de sílabas (los hay desde los que superan la treintena de sílabas hasta un tetrasílabo), que van agrupándose en nueve bloques estróficos tampoco equivalentes, ya que tres son de cuatro versos (los bloques 4, 6 y 9), dos detres (los bloques 1 y 5), uno de cinco (el bloque 7), uno de seis (el bloque 2), uno de siete (el bloque 3) y uno de ocho (el bloque 8). Las agrupaciones estróficas apresan enunciados que comienzan y terminan dentro de sus límites, salvo en el caso de los grupos sexto y séptimo, donde el discurso oracional prosigue en el siguiente bloque. Estos grupos no constituyen ninguna clase de estrofa preestablecida, y en cuanto a la rima no es posible asignarle ninguna; aunque a veces se den casos de rima interna como éstos:

su gran mano que rozaba las frentes unidas y las reconfortaba [v. 20],

Y ahora con el agua en la cintura todavía no se confía [v. 36].

La elección métrica aleixandrina habla de una importante libertad expresiva, una libertad que no desea el poeta conculcar enclaustrándose en una horma sancionada por la tradición, lo cual consigue reuniendo un cuerpo métrico muy

${ }^{10}$ id. nota 5, pp. 69-71. 
heterogéneo, que denota una transigencia muy acorde con el pensamiento del poema: todos caben, nadie ni nada sobra.

Con este dilatado versolibrismo, el autor quiere configurar otro ritmo, que remite a los elementos constituyentes del discurso poético, y que son los que imprimen un ritmo que no apabulla al lector, sino que más bien lo sustentan en la idea que se pretende comunicar, elementos unificadores que se repiten moderadamente "En la plaza", como la ausencia de sonidos roncos o desestabilizadores; la acentuación en primera o segunda sílaba de muchos versos; las enumeraciones; las series de aliteraciones en sibilantes; la abundancia de sustantivos y adjetivos/participios de pasado; la construcción polisindética (la conjunción copulativa " $y$ " aparece en 35 ocasiones), los paralelismos y construcciones anafóricas, la simetría sintagmática:

Allí cada uno puede mirarse y puede alegrarse y puede reconocerse [v. 24];

o la conduplicación que se advierte, por ejemplo, en:

Era una gran plaza abierta, y había olor de existencia.

Un olor a gran sol descubierto, a viento rizándolo,

un gran viento que sobre las cabezas pasaba su mano,

su gran mano que rozaba las frentes unidas y las reconfortaba [v. 17-20].

El versículo del poema es un verso libre mayor según la terminología acuñada por N avarro Tomás; un versículo coloquial, frecuentemente de generosa amplitud, porque lo que se canta en el poema es el valor de la gran colectividad humana, de la multitud entendida no como masa acéfala, sino como confluencia de deseos eilusiones, y en consecuencia adopta sobre el papel una visualización acorde con lo que se está representando: una manifestación. La largura del verso viene reclamada por el afán de transmitir una verbalización del entusiasmo. La longitud del versículo relajado en períodos largos, con abundantes descansos en las pausas se complementa con el versículo cortado por frases breves que producen cierta tensión dramática. Así, frente a un versículo sin paradas, y que muy bien pudiera haberse traído a colación para lo expuesto líneas arriba sobre el paralelismo interno, como:

Allí cada uno puede mirarse y puede alegrarse y puede reconocerse [v. 24],

nos encontramos con un verso como el que se copia seguidamente:

La gran masa pasaba. Pero era reconocible el diminuto corazón afluido [v. 13].

El versículo de "En la plaza” es un verso casi doméstico, al modo de una 
conversación entre el yo público y el propio yo psicológico; un versículo en el que el poeta va enhebrando con sobrada naturalidad un léxico eficaz por lo cercano, un vocabulario en absoluto envarado, dondela variedad de vocablos es sustituida por términos muy del gusto al eixandrino: todos las palabras resultan de una llaneza paradigmática, como ratifica un sencillo muestreo de adjetivos ("puro", "sereno", "pequeño", "desnudo", "poderoso", "silenciosa", "existente", "bueno", etc.) o nombres comunes ("ojos", "viento", "tarde", "corazón", "boca", "espejo", "agua", "brazos", "plaza", "mano", etc. $)^{11}$. El versículo de "En la plaza" está descargado de solemnidades retóricas, es un versículo inclinado a la repetición de estructuras análogas, que desparrama los contenidos y los recoge para volver a extenderlos en otra dirección; un versículo con música interna que va acumulando paralelismos próximos o distanciados. En el verso quinto escribe que no es bueno "quedarse en la orilla", y en el séptimo que es mejor "arrasarse en la dicha", dondela construcción verbo reflexivo+preposición+artículo+nombre común se repite. 0 tro ejemplo lo descubrimos en los versos 14-15:

\section{(...) Allí con esperanza, con resolución, con fe, con temeroso denuedo,} con silenciosa humildad (...),

donde a la forma preposición+nombre abstracto de los tres primeros elementos enumerados (esperanza, resolución, fe) le sigue la conformada por preposición tepíteto tnombre abstracto.

Los versículos del poema denotan un espíritu reposado, y esta fluidez únicamente se trastoca en una ocasión, al final del tercer grupo estrófico a causa deun encabal gamiento abrupto, dondeel enunciado del verso penúltimo seinterrumpe para dar entrada en el siguiente a una única forma verbal en imperfecto: "transcurría" [v. 16], y ello para subrayar que entrela muchedumbre, entrela comunidad indiferenciada también el hombre puede encontrar su autonomía, su parcela pensantey discrepadora. El poema contieneotro encabal gamiento localizable en el verso octavo:

Sino que es puro y sereno arrasarse en la dicha de fluir y perderse, [w. 7-8].

Los versículos de "En la plaza” están despojados de imágenes superrealistas, pues el impulso lírico que le conducía a crear imágenes sorprendentes deja paso ahora a una veta más narrativa, donde la lengua poética se esponja y anhela el

${ }^{11} \mathrm{EI}$ crítico V icente G aosha detectado una relación entreel vocabulario usado por Aleixandre y el caudal léxico de Fray Luis de León. 
contacto directo con la realidad histórica, avanza la poesía de la "G eneración del $50 "$, tal y como puede apreciarse en los siguientes versos:

Como ése que vive ahí, ignoro en qué piso, y le he visto bajar por unas escaleras

y adentrarse valientemente entre la multitud y perderse [vv. 10-12].

"En la plaza" se abre, en su primer bloque estrófico, con la radiante expresión desentirse felizmentearrastrado por la multitud; el poeta se siente arrastrado sin poder evitarlo, pero es una imposición agradable como nos señala la aliteración del verso 3: "rumorosamente arrastrado"; el poeta se encuentra dentro de esa muchedumbre que se manifiesta: el tapiz semántico de acción y movimiento es extenso y urdido por todo el poema. Comienza el poema con un hipérbaton contundente: "H ermoso es", con el que se fija el carácter decisivo y bello de todo lo que va a exponerse en lo venidero. La elección hiperbatónica sólo tendrá continuación en el poema en el siguiente bloque. En otra parte del poema nos encontramos con un caso de hipérbaton raro, en tanto que no se explica a no ser como antídoto contra la sinalefa de haberlo puesto el autor después del verbo; el verso en cuestión es éste:

\section{quisieras algo preguntar a tu imagen [v. 27].}

La apertura del primer grupo estrófico ("H ermoso es, hermosamente humilde (...)") tiene una analogía matemática con el primer verso de otro poema deH istoria del corazón, el titulado "Como un vilano", queinaugura el poemario, y donde se lee: "H ermoso es el reino del amor"12. Sin embargo, la pausa que "En la plaza" se introduce con el signo de puntuación de la coma hace el enunciado mucho más contundente. En esteprimer bloqueya apareceel gusto aleixandrino por los grupos deadjetivos o por las parejas de adjetivotadjetivo adverbial izado.

Pasa el poeta en el segundo bloque a criticar la inconveniencia del aislamiento y los beneficios de estar integrado en la comunidad. Es un bloque montado sobre la oposición y el contraste: oposición entrela construcción lingüística "no es" y "sino que es", a cada uno de cuyos segmentos les corresponden tres versos; oposición entre la concreción dela "orilla", el "malecón" o la "roca", y la abstracta sensación de "dicha"; oposición incluso entreel acto de "imitar a la roca", que es una mímesis improductiva, y el "pal pita extendido", cargado de sentimiento y capacidad regenerativa.

En el tercer bloque, el poeta personaliza en un ciudadano cualquiera esta inserción en la muchedumbre, que se dirige con al egría festiva y ansia de justicia

${ }^{12}$ Vid. nota 5, p. 9. 
social a un sitio, la plaza del título. En este bloque ya se introducen variantes en las formas verbales, pese a la prevalencia todavía de la tercera persona. El espacio público de la plaza copa la atención del cuarto grupo estrófico, una plaza quees, además, grande y abierta, lugar de concordia y celebración. No hay avance temático, sólo explicitación de una percepción ilusionante que desata algo a lo que no se le da rostro textual.

En el grupo estrófico quinto se ensancha todavía más la impresión de euforia ilimitada, de superación de barreras cuando la muchedumbre minimiza con su presencia espacios de cierta limitación física como la plaza, ya que las gentes anónimas cubren completamenteel piso de la plaza, ésta deja de existir como tal ante la presencia de los hombres.

Llega entonces en los grupos sexto y séptimo el reconocimiento de cada cual, una vez que se ahoga la egolatría y el narcisismo individualista, cuando exclama el poeta tomándose como ejemplo:

no te busques en el espejo,

en un extinto diálogo en que no te oyes [w. 28-29].

A partir del sexto bloque se muda aparentemente el receptor con la aparición de una segunda persona que en realidad es un correlato del yo poético, debido probablemente a la pretensión del poeta de no capitalizar su posición dentro del enunciado. G racias a esta técnica, se crea una ambival encia de eficacia expresiva alta.

En el octavo bloque estrófico se demora en la transformación y los efectos placenterosque proporciona el asumir la nueva identidad como molécula de un átomo social regenerador, para lo cual utiliza el símil de un bañista (coincidiendo aquí con Walt W hitman) que se introduce en el mar, un mar que recuerda los vidas-ríos manriqueños, y del que sale completamente transformado como indica ese final estrófico "y es joven", que se impregna de modo tan intenso en la retina del lector. El mar aleixandrino es, como en muchos otros, medio seminal y de purificación por excelencia, donde se producirá un nuevo nacimiento, un desvelamiento de otra real idad radical mente distinta y enriquecedora. Será entonces cuando el dinamismo negativo de las estrofas precedentes (alimentado con las tiradas adjetivas y las subordinaciones), configuradas según una técnica dilatoria, de paso a una progresión, a un dinamismo positivo, provocado por la aglomeración verbal, ya que en tan sólo ocho versos, Aleixandre utiliza veinte formas verbales, siempre en presente de indicativo. La colocación de los verbos al final de cuatro delos versos hace que psicológicamenteel lector conceda primacía a la acción, al movimiento, a la iniciativa que el texto pretende incrustar en la conciencia del lector. Los elementos que podríamos considerar de filiación más o 
menos marítima, o relacionados con lo acuático, se desparraman por el poema, con sustantivos como "bañista", "agua", "espuma", "torrente", etc.; adjetivos como "afluido" o "mezclado"; y formas verbalescomo "introduce", "selanza", "fúndete". Lo acuático puede tomarse aquí como moderada alusión al amor sexual, encarnando la penetración del cuerpo anónimo e individual en el cuerpo comunitario, en una concentración totalizadora. Lo líquido del mar se contrapone a lo pétreo de la plaza, lo que está en constante cambio y renovación, oreando el entorno y mudándose, se contraponeasí al estatismo inamovible, desgastado y anacronizante.

El último bloque es una invitación imperiosa a formar parte de la multitud, que pone el brocheen una exclamación de poderosa fuerza expresiva, en la que se repite por tres veces una palabra clave como "corazón", término al que, por única vez en todo el poema, se le antepone y pospone un calificativo gradatorio. Concluye el discurso poético ascensionalmente, cuando el hombre inicia su metamorfosis, ya que el primer hemistiquio puede tomarse como una acción que acaba de comenzar: "Así, entra con pies desnudos". El adverbio modal nos da pie para suponerlo. Al rematar el autor su composición con la forma verbal "alcanza", creo que logra solidificar en las prioridades lectoras un ansia: que se Ileguea una concordia civil. C on esteúltimo bloquela organización de contenidos del poema podemos tomarla como dotada de cierto sentido circular, ya que el primer y el último grupo estrófico se osmotizan: el último bloque es más indeciso que el primero, pues apunta hacia una aspiración que en el primer bloque talmente parece conseguido.

El ideal de fusión, mezcla o simbiosis entre el individuo y la multitud es convocado, en diversas ocasiones, con un tono que sube conforme se refieren las ventajas de esta comunión. Veámoslo en estos versos:

Y era el serpear que se movía como un único ser, no sé si desvalido, no sé si poderoso, pero existente y perceptible [vv. 21-23];

0 en éste:

O h, desnúdate y fúndete, y reconócete [v. 32];

o mismamente en la exclamación final, donde ya lo particular está a punto de fundirse con lo universal, el "corazón diminuto" con el "unánime corazón", y donde la disposición del epíteto no es aleatoria:

¡O h pequeño corazón diminuto, corazón que quiere latir para ser él también el unánime corazón que le alcanza! [w. 43-44].

Al mezclarse, el hombre desciende del pedestal que le impedía comprender 
la realidad en toda su dimensión, como se recoge en el verso 30: "Baja, baja despacio y búscate entre los otros". I ncrustarse en la riada colectiva, lejos de ser una renuncia, es un reforzamiento de las propias aspiraciones. La comunidad se concretiza en indefiniciones como "los otros", "Ios demás", "un único ser", "la gran masa". Esta fusión con los demás parece remitir en Aleixandre a moldes ascético-místicos, dado el sentido electrizante imparable de esta ceremonia, tal y como se aprecia en el arranque del poema:

sentirse bajo el sol, entre los demás, impelido,

llevado, conducido, mezclado, rumorosamente arrastrado [w. 2-3].

Con todo, en el poema no se consuma de forma completa el ensamblaje de los hombres con sus semejantes, sino que se incita continuamente a ello, y la última estrofa deja en suspensión la consumación a la que el corazón humano, el hondo sentir de los hombres, no quiere resistirse. $\mathrm{H}$ ay una llamada encandiladora que el hombre ansía corresponder. Leemos en el verso 42:

Entra en el torrente que te reclama y allí sé tú mismo.

Las singularidades individuales de los hombres forman así un todo compacto, una nueva singularidad colectiva no aislada que revitaliza la condición de cada cual y de toda la generalidad. Así, los hombres se hacen realmente conscientes de su lugar en el mundo en que se desenvuelven; Aleixandre viene a decirnos que el hombre no es completamente humano hasta que no se fusiona con sus prójimos semejantes, adquiriendo, entonces, una humanidad más humana. Al anular su entidad individual, asumen el sentir general y se sienten renovados, precisan de la solidaridad para caminar con un objetivo fijo y poder salvar los obstáculos que se les presenten. D esde un punto de vista pragmático, el poema pudo muy bien calar en el receptor como revulsivo contra la cobardía social en la España de la inmediata posguerra. En esta llamada a la unidad, no hay huella política al guna, porqueA leixandre lo que ha hecho ha sido transportar un hecho puntual de su juventud (proclamación de la II República) a otra tesitura.

Al hombre no le basta con "conocer", ya que en el "reconocerse" se limpia de impurezas y aspira a otra percepción del mundo. El crítico italiano D ario Puccini afirma que "en la acción del 'reconocerse' y del 'reconocer' toma cuerpo y se resuelve la conciencia de la crisis, o sea, la amplia insatisfacción existencial del poeta"13. El campo semántico del "reconocimiento" no es potestativo de este

${ }^{13}$ Puccini, D arío: La palabra poética deVicenteAleixandre, Barcelona, Editorial Ariel, 1979, pp. 208-209. 
poema sino que aparece estructurando la materia de otros poemas de $\mathrm{H}$ istoria del corazón como los titulados "Ten esperanza", "El otro dolor", "La explosión", "Ante el espejo", "El poeta canta por todos", "La clase", o en el titulado "En la oscuridad", donde Aleixandre ha escrito un verso que no disonaría absolutamente nada de haberlo incluido el autor en el poema que analizamos:

Una sola criatura viviente, padecida, de la que cada uno, sin saberlo, es totalmente [solidario ${ }^{14}$.

En el poema en el que nos hemos detenido como un ejemplo posible en la obra al eixandrina de modulación moral con miras sociales, el "reconocerse" aparece en forma adjetiva (v. 13), y verbal, bien como infinitivo (v. 24), imperativo (v. 32) o presente de indicativo (v. 38). La variedad rebaja la hipotética insistencia machacona de una forma única y dota a las pretensiones líricas de una sugestión que coadyuva a la meta perseguida por el poeta.

${ }^{14}$ Vid. nota 5, p. 86. 